\section{Photodynamic therapy with verteporfin for polypoidal choroidal vasculopathy}

M-W Lee, I Yeo, D Wong and C-L Ang

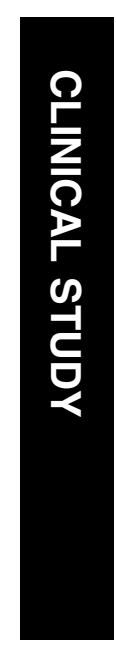

primary abnormality involved the choroidal circulation and the pathogenesis was unknown. Characteristically, there is a branching vascular network with 'polyp-like' saccular dilatations that is clinically visible as subretinal reddishorange spherical lesions. Affected individuals may experience recurrent retinal pigment epithelium detachments (PEDs) and subretinal haemorrhages secondary to leakage from these vascular lesions.

This unique disease seems to preferentially affect pigmented races and was first described in African-American women. ${ }^{2}$ Subsequently, individuals of Asian descent were also found to have increased predisposition for this disorder. ${ }^{3,4}$ The pathogenesis of PCV is still not fully understood and the abnormality is believed to originate from the inner choroid where studies have shown that the dilated tortuous aneurysmal vessels were of venular origin. 5 These choroidal lesions have also been described to occur in different locations:

peripapillary, macula, temporal vascular arcade, or mid-periphery. ${ }^{7-9}$

There has been no consensus about the treatment for PCV. Some polyps remain quiescent and, when managed conservatively, they have spontaneously resolved over time with preservation of good vision. ${ }^{10}$ However, loss of vision can become permanent in some patients with PCV, which is complicated by recurrent haemorrhages or PEDs affecting the macula. Many different treatment modalities have been used in an attempt to preserve vision in these patients. Direct laser photocoagulation, ${ }^{11-14}$ transpupillary thermotherapy, ${ }^{15}$ photodynamic therapy (PDT), ${ }^{16-21}$ and vitreoretinal surgery ${ }^{22,23}$ are some of the modalities that have been described.

Few reports of PDT for PCV have been described. ${ }^{16-21}$ The majority of these studies have reported evidence of a beneficial effect
Department of Vitreoretinal Surgery, Singapore National Eye Centre, Singapore, Singapore

Correspondence: C-L Ang, National Eye Centre, 11 Third Hospital Avenue, Singapore 168751, Singapore

Tel: + 6562277255 ; Fax: + 6562277290

E-mail: ang.chong.lye@ snec.com.sg

Received: 16 April 2008 Accepted in revised form: 9 July 2008

Published online: 29 August 2008

This paper was presented at the 2006 Cannes Retinal Festival, European Vitreoretinal Society and American Society of Retinal Specialists combined meeting. This paper has not been published or submitted for publication in any other journals Financial support: None Proprietary interests: None Vitreoretinal, Singapore
Polypoidal choroidal vasculopathy (PCV) was first described by Yanuzzi and colleagues. ${ }^{1}$ The 
with PDT. In our study, we report the outcomes of patients with symptomatic PCV treated with PDT with verteporfin after a mean follow-up of almost 2 years.

\section{Materials and methods}

This was a retrospective analysis of an interventional case series aimed at evaluating the efficacy of PDT for the treatment of serosanguinous maculopathy secondary to PCV. Case records of patients who presented to a tertiary ophthalmic centre (Singapore National Eye Centre) with symptomatic PCV and subsequently underwent PDT with verteporfin were reviewed. Institutional review board approval was not required at the time this study was conducted.

Only patients who had at least 12 months of follow-up were included. All eligible patients had indocyanine green (ICG) angiographically proven subfoveal or juxtafoveal polypoidal lesions with associated serosanguinous maculopathy defined as the presence of subretinal haemorrhage and/or retinal pigment epithelial detachment and/or serous neurosensory detachment affecting the macula. Patients who had previous extrafoveal PCV, which resolved spontaneously or who had been treated with argon laser and subsequently suffered a juxtafoveal or subfoveal recurrence of PCV, were also included. All patients underwent PDT with verteporfin. Best-corrected visual acuity (BCVA) was recorded before treatment and at each follow-up visit. All BCVA measurements were in Snellen acuity and for purposes of analysis, these were converted to logarithm of minimal angle of resolution ${ }^{24}(\log M A R)$ equivalent values. Counting fingers (CFs) and hand movement vision were allocated logMAR equivalents of 2.00 and 3.00, respectively. Primary outcome measure at last follow-up was clinical or angiographic evidence showing resolution of maculopathy with or without associated improvement in visual acuity. Secondary outcome measure was the BCVA at last follow-up.

Photodynamic therapy with verteporfin was given according to guidelines described in the Treatment of Age-related macular degeneration with Photodynamic therapy study. ${ }^{25}$ The greatest linear dimension was measured to cover the whole area of abnormalities, including the polypoidal lesions and the interconnecting vessels according to ICG angiography. A standard verteporfin (Visudyne, Novartis) infusion followed by laser application of $689 \mathrm{~nm}, 50 \mathrm{~J} / \mathrm{cm}$ for $83 \mathrm{~s}$ was done.

\section{Results}

\section{Patient characteristics}

Forty-one eyes of 40 patients were included in this study (Table 1). There were 21 male participants (52.5\%) and 19 female participants. Thirty-five patients (87.5\%) were Chinese, four were Malay, and one was Indian. The mean age at presentation was 68.4 years ranging from 44 to 92 years. There were $29(70.7 \%)$ right eyes and 12 left eyes, which underwent treatment. The mean visual acuity at presentation was $0.75 \log$ MAR (range 0.04-2.00).

\section{Visual outcomes}

The mean follow-up was 23.9 months and at the last follow-up visit, seven eyes $(17.1 \%)$ had improved vision $\geqslant 3$ lines and five eyes $(12.2 \%)$ had improvement of vision $<3$ lines (Figure 1). The mean logMAR improvement was 0.45 . Twelve eyes $(29.2 \%)$ had stable vision (lost of $\leqslant 3$ lines) with a mean logMAR change of 0.04 . Seventeen eyes $(41.4 \%)$ had decreased vision (lost $>3$ lines) and the mean logMAR decrease was 1.06 .

There were 31 eyes $(75.6 \%)$ with angiographically determined subfoveal and 10 eyes (24.4\%) with juxtafoveal polypoidal lesions. In the subfoveal group, eight eyes (25.8\%) showed improved vision (mean $\log$ MAR improvement $=0.54)$. Nine eyes $(29 \%)$ had stable vision (mean logMAR change $=0.03$ ) and 14 eyes $(45.2 \%)$ had decreased vision (mean logMAR decrease $=1.19$ ).

In the juxtafoveal group, four eyes (40\%) had improved vision (mean logMAR improvement $=0.26$ ) Three eyes remained stable after treatment (mean logMAR change $=0.06$ ) and three eyes had decreased vision (mean logMAR decrease $=1.02$ ).

The mean number of treatments was 1.92 . The mean interval between treatments was 23.4 weeks.

\section{Resolution of maculopathy}

Thirty-three eyes (80.4\%) had clinical and/or angiographic evidence of complete resolution of maculopathy at the last follow-up. Twenty-three of these 33 eyes also had associated stabilisation or improvement of BCVA. Seven of these 23 eyes had juxtafoveal lesions.

Ten eyes $(24.3 \%)$ had recurrence of polyps, defined as a recurrence of maculopathy $>6$ months after the last treatment, of which seven eyes had previously treated subfoveal lesions. The mean interval to recurrence of maculopathy in these patients was 13.7 months. Five of these 10 eyes lost $>3$ lines of vision at last follow-up and four eyes still had some persistent maculopathy.

There were six eyes $(14.6 \%)$ that developed subsequent subfoveal choroidal neovascularisation ( $\mathrm{CNV})$; two of which had persistent maculopathy at last follow-up.

\section{Case report}

A 76-year-old Chinese lady presented with sudden painless loss of vision in her left eye of 10 days duration. 
Table 1 Patient characteristics

\begin{tabular}{|c|c|c|c|c|c|c|c|c|}
\hline No. & Gender & Age & Location & Baseline VA & $V A$ last $F / U$ & Last F/U mth & $\log M A R$ change & No of $R x$ \\
\hline 1 & $\mathrm{~F}$ & 79 & Subfoveal & 2.00 & 0.62 & 33 & $-1.38^{\mathrm{a}}$ & 1 \\
\hline 2 & $\mathrm{~F}$ & 66 & Subfoveal & 1.00 & 0.02 & 18 & $-0.98^{\mathrm{a}}$ & 1 \\
\hline 3 & F & 60 & Subfoveal & 1.00 & 0.48 & 15 & $-0.52^{\mathrm{a}}$ & 1 \\
\hline 4 & F & 55 & Subfoveal & 0.66 & 0.04 & 41 & $-0.52^{\mathrm{a}}$ & 2 \\
\hline 5 & $\mathrm{~F}$ & 56 & Juxtafoveal & 0.58 & 0.18 & 18 & $-0.40^{\mathrm{a}}$ & 2 \\
\hline 6 & F & 66 & Subfoveal & 0.40 & 0.00 & 12 & $-0.40^{\mathrm{a}}$ & 1 \\
\hline 7 & $\mathrm{~F}$ & 44 & Juxtafoveal & 0.40 & 0.04 & 24 & $-0.36^{\mathrm{a}}$ & 1 \\
\hline 8 & M & 67 & Subfoveal & 0.40 & 0.12 & 12 & $-0.28^{\mathrm{a}}$ & 1 \\
\hline 9 & M & 70 & Subfoveal & 0.30 & 0.12 & 21 & $-0.18^{\mathrm{a}}$ & 3 \\
\hline 10 & $\mathrm{~F}$ & 59 & Juxtafoveal & 0.20 & 0.04 & 12 & $-0.16^{\mathrm{a}}$ & 1 \\
\hline 11 & M & 58 & Juxtafoveal & 0.14 & 0.00 & 15 & $-0.14^{\mathrm{a}}$ & 1 \\
\hline 12 & M & 64 & Subfoveal & 0.38 & 0.30 & 27 & $-0.08^{\mathrm{a}}$ & 3 \\
\hline 13 & $\mathrm{~F}$ & 85 & Juxtafoveal & 2.00 & 2.00 & 18 & 0.00 & 1 \\
\hline 14 & M & 72 & Subfoveal & 2.00 & 2.00 & 28 & 0.00 & 1 \\
\hline 15 & $\mathrm{~F}$ & 72 & Subfoveal & 0.04 & 0.04 & 34 & 0.00 & 1 \\
\hline 16 & $\mathrm{~F}$ & 82 & Subfoveal & 0.22 & 0.22 & 41 & 0.00 & 4 \\
\hline 17 & M & 79 & Subfoveal & 2.00 & 2.00 & 24 & 0.00 & 3 \\
\hline 18 & M & 60 & Subfoveal & 1.30 & 1.30 & 21 & 0.00 & 1 \\
\hline 19 & M & 66 & Subfoveal & 0.88 & 0.88 & 30 & 0.00 & 1 \\
\hline 20 & M & 73 & Subfoveal & 2.00 & 2.00 & 27 & 0.00 & 2 \\
\hline 21 & M & 66 & Juxtafoveal & 0.12 & 0.18 & 21 & 0.06 & 1 \\
\hline 22 & $\mathrm{~F}$ & 73 & Subfoveal & 0.60 & 0.70 & 18 & 0.10 & 2 \\
\hline 23 & M & 64 & Juxtafoveal & 0.58 & 0.70 & 39 & 0.12 & 2 \\
\hline 24 & $\mathrm{~F}$ & 69 & Subfoveal & 0.40 & 0.60 & 24 & 0.20 & 2 \\
\hline 25 & $\mathrm{~F}$ & 51 & Subfoveal & 0.24 & 0.70 & 27 & 0.46 & 2 \\
\hline 26 & $\mathrm{~F}$ & 85 & Subfoveal & 0.40 & 0.88 & 18 & 0.48 & 1 \\
\hline 27 & M & 68 & Subfoveal & 0.52 & 1.02 & 34 & 0.50 & 3 \\
\hline 28 & M & 81 & Juxtafoveal & 0.78 & 1.30 & 21 & 0.52 & 2 \\
\hline 29 & $\mathrm{~F}$ & 68 & Subfoveal & 1.30 & 2.00 & 30 & 0.70 & 1 \\
\hline 30 & M & 80 & Subfoveal & 1.30 & 2.00 & 24 & 0.70 & 2 \\
\hline 31 & M & 71 & Juxtafoveal & 0.56 & 1.30 & 21 & 0.74 & 2 \\
\hline 32 & $\mathrm{~F}$ & 59 & Subfoveal & 0.50 & 1.30 & 12 & 0.80 & 2 \\
\hline 33 & M & 56 & Juxtafoveal & 0.48 & 1.30 & 12 & 0.82 & 2 \\
\hline 34 & $\mathrm{~F}$ & 61 & Subfoveal & 0.30 & 1.30 & 21 & 1.00 & 1 \\
\hline 35 & M & 92 & Subfoveal & 2.00 & 3.00 & 12 & 1.00 & 2 \\
\hline 36 & $\mathrm{~F}$ & 78 & Subfoveal & 0.70 & 2.00 & 24 & 1.30 & 3 \\
\hline 37 & M & 66 & Subfoveal & 0.70 & 2.00 & 30 & 1.30 & 2 \\
\hline 38 & M & 69 & Subfoveal & 0.44 & 2.00 & 18 & 1.56 & 4 \\
\hline 39 & $\mathrm{~F}$ & 71 & Subfoveal & 0.26 & 2.00 & 34 & 1.74 & 4 \\
\hline 40 & F & 76 & Subfoveal & 0.56 & 3.00 & 31 & 2.44 & 1 \\
\hline 41 & F & 66 & Subfoveal & 0.30 & 3.00 & 39 & 2.70 & 6 \\
\hline
\end{tabular}

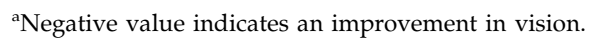

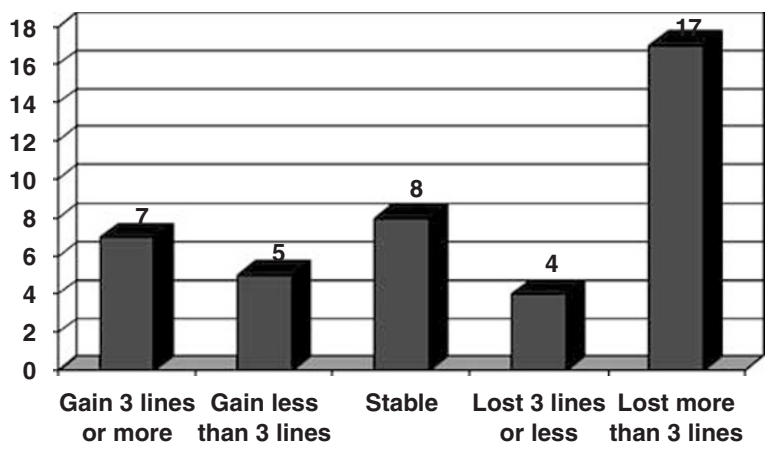

Figure 1 Visual outcomes after PDT at last follow-up.
Visual acuities were CFs in her right eye due to a previously noted disciform macular scar and 6/60 in her left eye with clinical evidence of a submacular haemorrhage and pigment epithelial detachment. Fluorescein and ICG angiography showed the presence of subfoveal polypoidal lesions (Figure 2). She underwent PDT with verteporfin and 3 months after treatment, there was resolution of the subretinal haemorrhage and PED with only a rim of exudates remaining. Angiography showed complete resolution of the polypoidal lesions (Figure 3). Her BCVA had improved to 6/48. At her last follow-up, 4 years after 


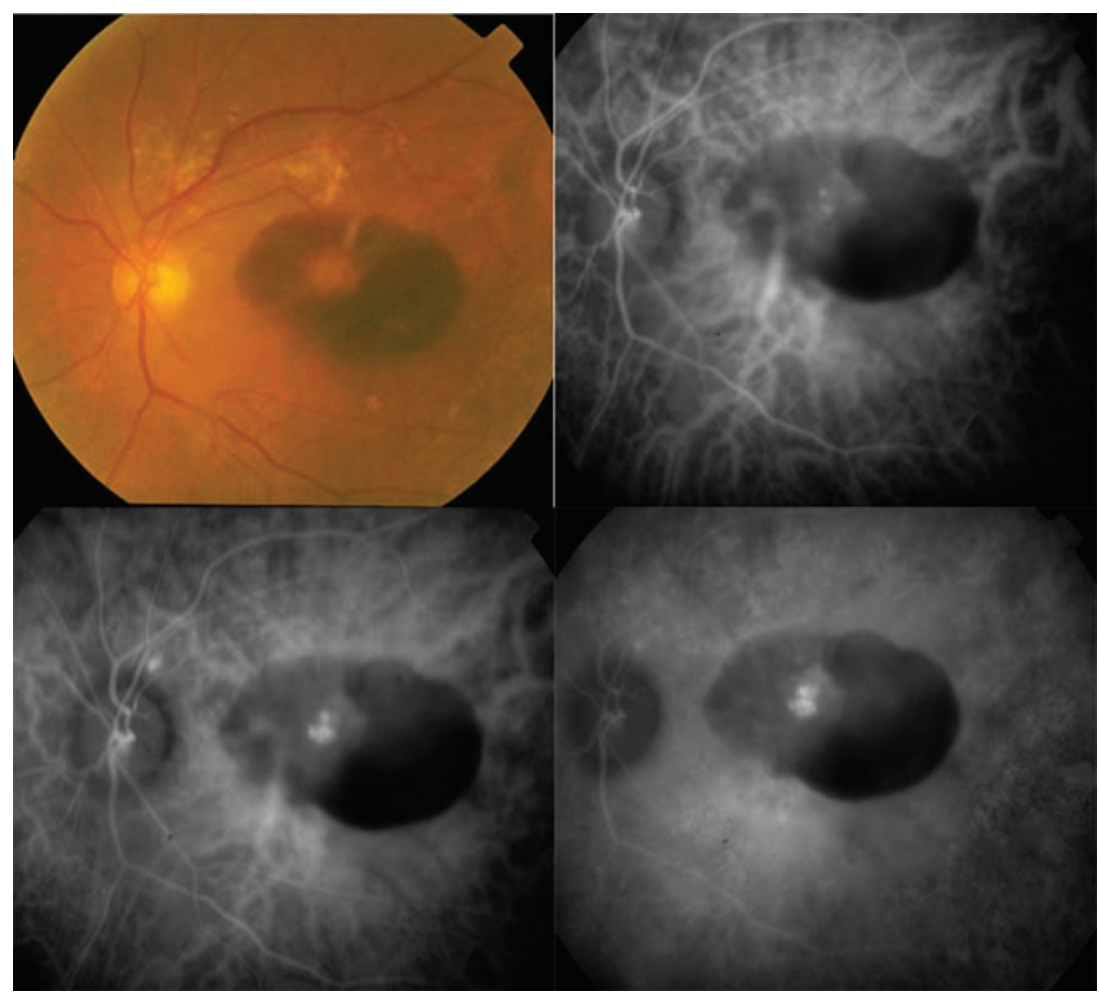

Figure 2 Color fundus photo and indocyanine angiography of patient's left eye showing a submacular haemorrhage and a cluster of subfoveal polyps.

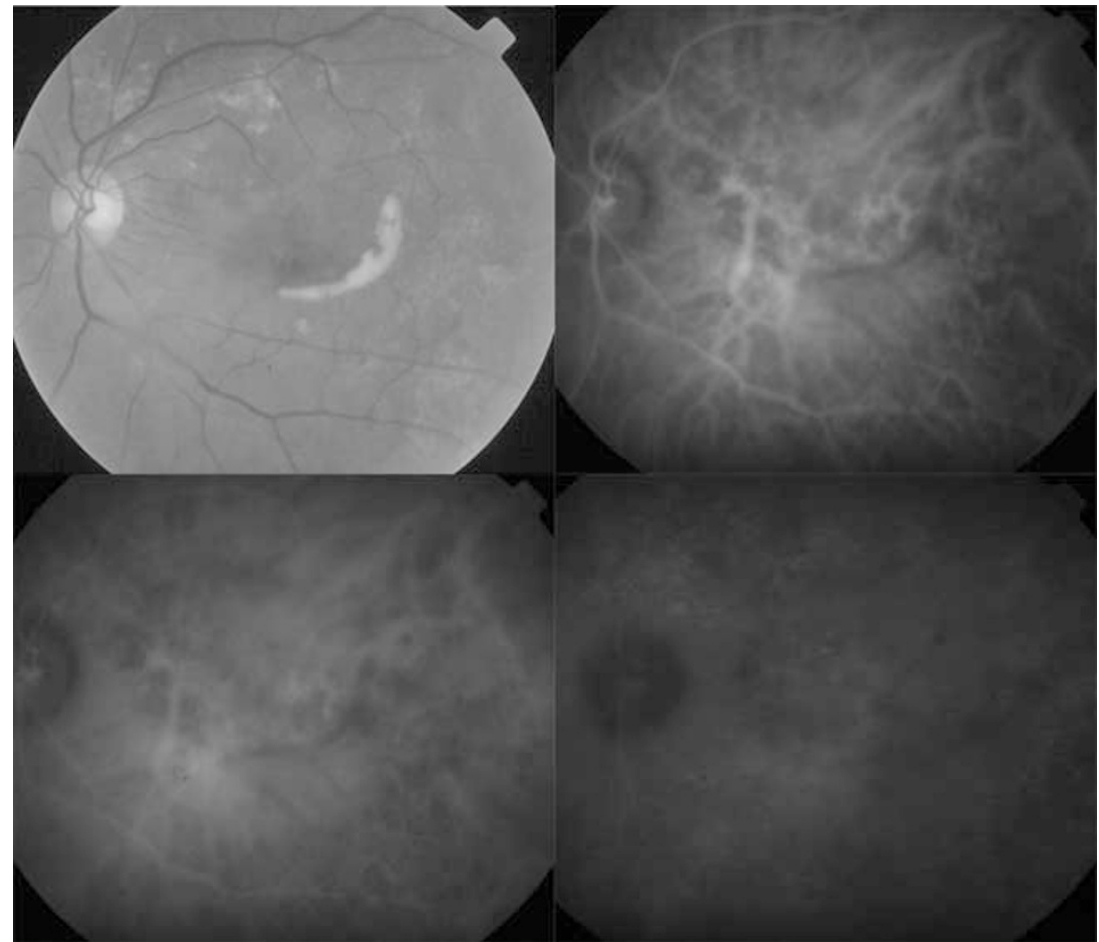

Figure 3 The same patient's left eye 3 months after PDT showing resolution of the haemorrhage and polypoidal lesions. 
treatment, her BCVA was $6 / 21$ and there was no evidence of any recurrence.

\section{Discussion}

The pathogenesis of PCV is still not completely understood. Persistent leakage from these lesions can lead to chronic pigment epithelial and neurosensory detachments as well as recurrent haemorrhages and in some circumstances, a breakthrough vitreous haemorrhage. ${ }^{17}$ Ultimately, there can be permanent visual loss from atrophy and degeneration of the retinal pigment epithelium and outer retina.

The natural history of PCV has not been extensively described. However, what little has been reported tends to point towards an unfavourable outcome with observation alone. Yuzawa et $a l^{11}$ reported that only 5 of 21 eyes (24\%) with PCV involving the macula had visual improvement with conservative management over a follow-up period of 3 years (IOVS 42(supp): S800, 2001). Uyama et $a l^{10}$ reported that 5 of 14 eyes (36\%) lost more than 2 lines of vision over a follow-up period of 2 years. Kwok $e t a l^{26}$ also described a loss of vision of 2 lines or more in seven of nine eyes $(78 \%)$ that had PCV involving the macula and were managed conservatively. Therefore, in most instances where patients have significant symptomatic visual loss, treatment is often considered.

Photodynamic therapy has been extensively used in the treatment of $\mathrm{CNV}$, and its use in the treatment of PCV has also been reported. ${ }^{16-21}$ In a case series of 22 eyes in 21 Chinese patients with PCV reported by Chan et al, ${ }^{16}$ $95 \%$ of eyes achieved stable or improved vision and $45 \%$ of eyes had improvement of $\geqslant 3$ lines at 1 year follow-up. Unfortunately, we were unable to mirror these excellent results as in our series of 41 eyes in 40 Asian patients with a mean follow-up of almost 2 years, only 24 eyes (58.5\%) achieved stable or improved vision. Moreover, we report a recurrence of polypoidal lesions and serosanguineous maculopathy in almost $25 \%$ of patients after a mean interval of 13.7 months after the last PDT treatment. The large disparity between our results could be attributed to our less-stringent study exclusion criteria as we had not excluded patients who had previous focal argon laser treatment for extrafoveal PCV. There were five patients with previously treated extrafoveal PCV of which three had juxtafoveal and two had subfoveal recurrence. It is not established whether recurrent polyps would respond to PDT in the same way as fresh lesions would and therefore, this may confound our results. In our series, all our patients had either juxtafoveal or subfoveal polypoidal lesions with associated serosanguineous maculopathy, whereas in the series described by Chan et al, ${ }^{16}$ four eyes had extrafoveal lesions of which three eyes improved more than 3 lines and the other remained stable. Considering that there were 10 eyes that improved 3 lines or more in their series, this would imply that $30 \%$ of the 'top gainers' in fact had extrafoveal lesions. This could result in a skew of their results towards a positive outcome. In a separate group of our PCV patients, we analysed 28 eyes with extrafoveal lesions that had focal laser treatment and we found that $75 \%$ of eyes achieved stable or improved vision at 12 months follow-up. ${ }^{27}$ Therefore, we believe that extrafoveal PCV should be first treated with focal argon laser photocoagulation.

We are aware of the limitations of our retrospective study that include the lack of standardised inclusion/ exclusion criteria and treatment protocol, the lack of a control group for comparison, and a variable follow-up period. However, our study did show that PDT of subfoveal or juxtafoveal polypoidal lesions for the treatment of symptomatic serosanguinous maculopathy seemed to offer stabilisation of vision and a moderate gain in vision for some patients and therefore, would still have a function in the treatment of this disease. Owing to the lack of natural history data, the course of this disease remains largely unknown and the true efficacy of any treatment would have to be assessed over a very long follow-up period. Going with the vogue of current antiangiogenesis treatments in AMD, it would also seem to be a logical progression to assess the efficacy of intravitreal vascular endothelial growth factor (VEGF) inhibitors for the treatment of PCV. There have been reports of some success of anti-VEGF for PCV but until confirmatory evidence from a randomised controlled trial is available, the best available treatment for this disease remains debatable.

\section{References}

1 Yanuzzi LA, Sorenson J, Spaide RF, Lipson B. Idiopathic polypoidal choroidal vasculopathy. Retina 1990; 10: 1-8.

2 Stern RM, Zakov N, Zegarra H. Multiple recurrent serous sanguineous retinal pigment epithelial detachments in black women. Am J Ophthalmol 1985; 100: 560-569.

3 Iijima H, Imai M, Gohodo T. Optical coherence tomography of idiopathic choroidal vasculopathy. Am J Ophthalmol 1999; 127: 301-305.

4 Lip PL, Hope-Ross MW, Gibson JM. Idiopathic polypoidal choroidal vasculopathy: a disease with diverse clinical spectrum and systemic associations. Eye 2000; 5: 695-700.

5 Lafaut BA, Aisenbrey S, van den Broecke C. Polypoidal choroidal vasculopthy pattern in age-related macular degeneration. Retina 2000; 20: 650-654.

6 Okubo A, Sameshima M, Uemara A. Clinicopathological correlation of polypoidal choroidal vasculopathy revealed by ultrastructural study. Br J Ophthalmol 2002; 86: 1093-1098.

7 Moorthy RS, Lyon AT, Rabb MF, Spaide RF, Yannuzzi LA, Jampol LM. Idiopathic polypoidal choroidal vasculopathy of the macula. Ophthalmology 1998; 105: 1380-1385. 
8 Yannuzzi LA, Ciardella A, Spaide RF, Rabb M, Freund KB, Orlock DA. The expanding clinical spectrum of idiopathic polypoidal choroidal vasculopathy. Arch Ophthalmol 1997; 115: $478-485$.

9 Spaide RF, Yannuzzi LA, Slakter JS, Sorenson J, Orlach DA. Indocyanine green videoangiography of idiopathic choroidal vasculopathy. Retina 1995; 15: 100-110.

10 Uyama M, Wada M, Nagai Y. Polypoidal choroidal vasculopathy; a natural history. Am J Ophthalmol 2002; 133: 639-648.

11 Yuzawa M, Mori R, Haruyama M. A study of laser photocoagulation for polypoidal choroidal vasculopathy. Jpn J Ophthalmol 2003; 47(4): 379-384.

12 Nishijima K, Takahashi M, Akita J, Katsuta H, Tanemura M, Aikawa $\mathrm{H}$ et al. Laser photocoagulation of indocyanine green angiographically identified feeder vessels to idiopathic polypoidal choroidal vasculopathy. $A m \mathrm{~J}$ Ophthalmol 2004; 137(4): 770-773.

13 Gomez-Ulla F, Gonzalez F, Torreiro MG. Diode laser photocoagulation in idiopathic polypoidal choroidal vasculopathy. Retina 1998; 18(5): 481-483.

14 Vilaplana D, Castilla M, Poposki V. Laser photocoagulation in idiopathic polypoidal choroidal vasculopathy. Over one year follow up. Arch Soc Esp Oftalmol 2005; 80(10): 597-602.

15 Vedantham V, Kolluru C, Ramasamy K. Treatment of polypoidal choroidal vasculopathy with transpupillary thermotherapy; an interventional case report. Eye 2005; 19(8): 915-917.

16 Chan WM, Lam DS, Lai TY, Liu DT, Li KK, Yao Y et al. Photodynamic therapy with verteporfin for symptomatic polypoidal choroidal vasculopathy: one year results of a prospective case series. Ophthalmology 2004; 111(8): 1176-1184.

17 Quaranta M, Mauget-Faysse M, Coscas G. Exudative idiopathic polypoidal choroidal vasculopathy and photodynamic therapy with verteporfin. Am J Ophthalmol 2002; 134: 277-280.
18 Spaide RF, Donsoff I, Lam DL, Yannuzzi LA, Jampol LM, Slakter J et al. Treatment of polypoidal choroidal vasculopathy with photodynamic therapy. Retina 2002; 22: 529-535.

19 Hussain N, Hussain A, Natarajan S. Role of photodynamic therapy in polypoidal choroidal vasculopathy. Indian J Ophthalmol 2005; 53(2): 101-104.

20 Silva RM, Figueira J, Cachulo ML, Duarte L, Faria de Abreu JR, Cunha-Vaz JG. Polypoidal choroidal vasculopathy and photodynamic therapy with verteporfin. Graefes Arch Clin Exp Ophthalmol 2005; 243(10): 973-979.

21 Rogers AH, Greenberg PB, Martidis A, Puliafito CA. Photodynamic therapy of polypoidal choroidal vasculopathy. Ophthalmic Surg Lasers Imaging 2003; 34(1): 60-63.

22 Shiraga F, Matsua T, Yokoe S, Takasu I, Okanouchi T, Ohtsuki $\mathrm{H}$ et al. Surgical treatment of submacular haemorrhage associated with idiopathic polypoidal choroidal vasculopathy. Am J Ophthalmol 1999; 128: 147-154.

23 Terasaki H, Miyake Y, Suzuki T, Nakamura M, Nagasaka T. Polypoidal choroidal vasculopathy treated with macular translocation: clinical pathological correlation. $\mathrm{Br} \mathrm{J}$ Ophthalmol 2002; 86: 321-327.

24 Holladay JT. Visual acuity measurements. J Cataract Refract Surg 2004; 30: 287-290.

25 Treatment of Age-Related Macular Degeneration with Photodynamic Therapy (TAP) Study Group. Photodynamic therapy of subfoveal choroidal neovascularization in agerelated macular degeneration with verteporfin. One year results of 2 randomized clinical trials - TAP report 1. Arch Ophthalmol 1999; 117: 1329-1345.

26 Kwok AK, Lai TY, Chan CW, Neoh EL, Lam DS. Polypoidal choroidal vasculopathy in Chinese patients. $\mathrm{Br} J$ Ophthalmol 2002; 86: 892-897.

27 Lee MW, Yeo I, Wong D, Ang CL. Argon laser photocoagulation for the treatment of polypoidal choroidal vasculopathy. Eye 2007; 24 August 2007 (e-pub ahead of print). 